\title{
SOA Based Municipal Information Management Basic Platform
}

\author{
Wen ZENG, Jianjun LV, Xincai WU \\ Faculty of Information Engineering, China University of Geosciences, Wuhan, China
}

\begin{abstract}
This paper proposed a digital municipal management platform based on service-oriented architecture. It aims to realize data sharing and system integration between the municipal enterprises. This platform adopts spatial information knowledge, network and database techniques, which includes hardware and software background layer, data layer, basic management layer, operation service layer and application layer. It supports multi-scale and multi-size data management, distributed multi structures, information updating, and application building and operation cooperation. The result shows that this platform with multi layers and diversified information service provides solid background for municipal enterprises and has been one the most important infrastructures for the digital municipal development and the combination of SOA and Grid Computing will be the trend for the municipal informationized development.
\end{abstract}

Keywords: municipal management; information integration; service oriented architecture (SOA)

\section{基於 SOA 的市政管理資訊化基礎平臺}

\author{
曾 文，呂建軍，吳信才 \\ 中國地質大學資訊工程學院，湖北 武漢
}

\begin{abstract}
摘 要：為了充分整合市政行業資源，實現市政行業企業級和城市級數據共用和系統集成，本文分析研究 了採用面向服務的架構設計數位市政管理基礎平臺。該平臺採用空間資訊學、網路和資料庫技術，包括軟 硬體支撐層、資料層、基礎管理層、運營服務層和應用層等多個層次，支援多源多尺度資料管理、分散式 多級體系、資訊長效更新、應用搭建和業務協同。該平臺採用多層次、多元化的資訊服務.為市政單位的 各項業務提供了有力支撑，是數字城市的重要基礎設施之一，同時 SOA 與網格計算（Grid Computing）相 結合，形成以服務為導向的網格計算是市政資訊化基礎平臺的方向。
\end{abstract}

關鍵字：市政管理；資訊集成；面向服務的架構（SOA）

\section{1. 前 言}

供排水、燃氣、道橋、照明、交通等市政行業與 市民生活息息相關, 是城市發展與社會穩定的重要保 障，目前普遍面臨缺乏統一規劃協調、事故頻發、運 行效益低下、漏失損耗巨大等問題。為此，國內外許 多城市都在加強市政管理的資訊化建設, 以提高市政 管理的整體水準。西方發達國家已經成功地將 GIS 技

基金專案: 國家十一五科技支撐計畫重點專案課題: 城市市政基礎 設施管理與運營關鍵技術研究與示範(No.2006BAJ15B03)
術、網路技術、資訊技術及視覺化監控管理技術應用 於市政管理，並極大地提高了其工作效率和管理力 度。如: 1988 年巴黎市政府開始建設城市資訊系統( 城 市地籍和地下管線管理資訊系統），主要用於協調城 市規劃和市政管理部門的工作；美國採用地理資訊系 統（GIS）進行市政管理，並對一些市政設施實現了 遠端監控; 美國、日本、歐洲等國家和地區分別採用 GIS 技術建設了相應的市政緊急事故處理系統。近年 來，國內部分市政管理水準較高的城市也相繼建立了 一些業務管理系統。如廣州市綜合管線管理系統、大 
連市城市路燈監控管理系統、寧波市供水管網管理系 統、常州市政公用地理資訊集成系統及北京東城區城 市網格化應用管理系統等, 提高了市政管理的工作效 率和管理水準。但是總體來看, 當前國內市政管理的 資訊化建設主要特點是局部建設、分散建設和重複建 設，相對於發達國家還比較落後。

市政管理資料龐大繁雜, 市政業務關聯緊密, 變更頻繁，資料和系統資源需要充分共用和有效組 合。因此，建立統一集成、靈活配置的的市政管理 資訊化基礎平臺，並在此平臺之上構建和整合應用 系統, 提供資訊服務, 才能更加切實地滿足市政管 理的需要。

市政管理資訊化基礎平臺建設的總體目標是: 利用空間資訊學技術、網路通訊技術、資料庫技術, 充分整合供水、燃氣、排水、供熱、道路、橋樑、 環衛、城市規劃等方面的資源, 構建一個集市政管 理、城市規劃與社會服務等綜合資訊為一體的多級 分散式數位市政管理資訊基礎平臺, 實現市政行業 企業級和城市級數據共用和系統集成; 建立切實可 行的資訊更新機制, 實現動態管理; 實現城市範圍 內市政資訊的綜合利用，有效支撑各項市政業務， 提高城市市政行業管理水準及公眾服務水準, 為政 府部門和業務管理部門提供及時、可靠的決策依 據，促進城市健康有序發展。

\section{2. 基礎平臺關鍵指標}

為了滿足市政規劃、管理、運營和服務的需要, 基礎平臺應滿足以下關鍵技術指標：

\section{1 多源多尺度資料管理}

市政管理資訊具有資料空間特徵強、對圖形資料要 求高、資料類型多、資料量大、涉及部門多、管理權屬 複雜等特點。例如就城市空間基礎地形而言, 從資料類 型看可能同時包含遙感影像、向量圖和三維景觀模型 等; 從資料尺度上, 可能同時包含多種投影多種比例尺 的資料層。又如，市政營業收費一般以月為核算單位， 但存在兩月抄表或季度抄表的情況; 即時監測資料獲取 間隔從數分鐘到幾小時，對應的分析報表包含日報、月 報、年報等多種時間粒度。這種資料狀況要求基礎平臺 具有海量、多源、多尺度資料管理能力。

\section{2 分散式多級資料管理體系}

市政管理和運營部門一般具有明顯的地域分佈特 徵, 分散在城市的不同地點, 造成資料分佈和應用分 佈的狀況。同時不同市政部門之間分工協作往往很緊
密，相互間的資訊依賴越來越強，對於集中共用資料 和應用, 有迫切的需求。另一方面, 市級和區級綜合 管理部門、市政企業、企業下級區所構成了市政多級 管理體制，決定了在資料獲取、管理和供給方面是分 層次的。例如一些大中城市供水企業有多個營業所, 對管網和用戶資料實施分區域管理，各分公司或營業 所負責維護使用本區域內的運營資料，供水總公司則 需要集中全局資料用於監控、規劃和決策。所以，市 政管理資訊化基礎平臺需要支援多級分散式資料管理 體系，如圖 1 所示。

\section{3 資訊長效更新}

市政資訊的長效更新一直是一個困難的問題。以 市政設施為例, 從上世紀九十年代初開始, 國內很多 城市投入鉅資進行管網普查建立了地下管線管理資料 庫。由於城市發展迅速, 這些資料庫很快失去了現勢 性, 難以體現使用價值。一些城市甚至反復多次進行 大規模管線普查，仍然難以阻止資料的過時。市政資 訊的長效更新是涵蓋制度、機制、標準、技術等諸多 方面的系統工程。過去往往強調前兩個方面, 而在標 準、技術方面的努力和嘗試比較欠缺。市政管理資訊 化基礎平臺需要解決標準和技術方面的問題, 並為相 應的管理制度提供支持。

曾文和張德津（2006）[1]提出了市政管理資訊的 網路分散式一體化管理技術，基本思路是以政府市政 綜合管理部門（如建設局）為依託，市政綜合資訊管 理服務中心，設立一級綜合資料伺服器。各個專業權 屬單位（供水公司、燃氣公司、排水管理處等）負責 專業資料的收集、整理、標準化、入庫，建立二級專 業資料庫, 並在運營活動（如管線的改造施工）中隨 時動態更新資料。二級專業資料庫及其變更資訊, 通 過篩選、過濾和綜合，動態反映到一級綜合資料庫， 從而維持後者的現勢性。各個專業單位保證自己權屬 的設施、業務資料現勢性的同時，又從綜合資料庫中 根據不同的許可權流覽到其他權屬單位的設施和業務 資料, 為自身的規劃設計、改造、施工提供重要的參 考依據。

\section{4 應用搭建和業務協同}

市政業務複雜多樣，相互關聯，流程規範經常發 生變更。市政管理系統需要在短時間內把用戶的應用 需求和應用知識轉變為電腦應用模型, 產生相應的應 用軟體和資料庫結構模式。市政基礎平臺應提供應用 


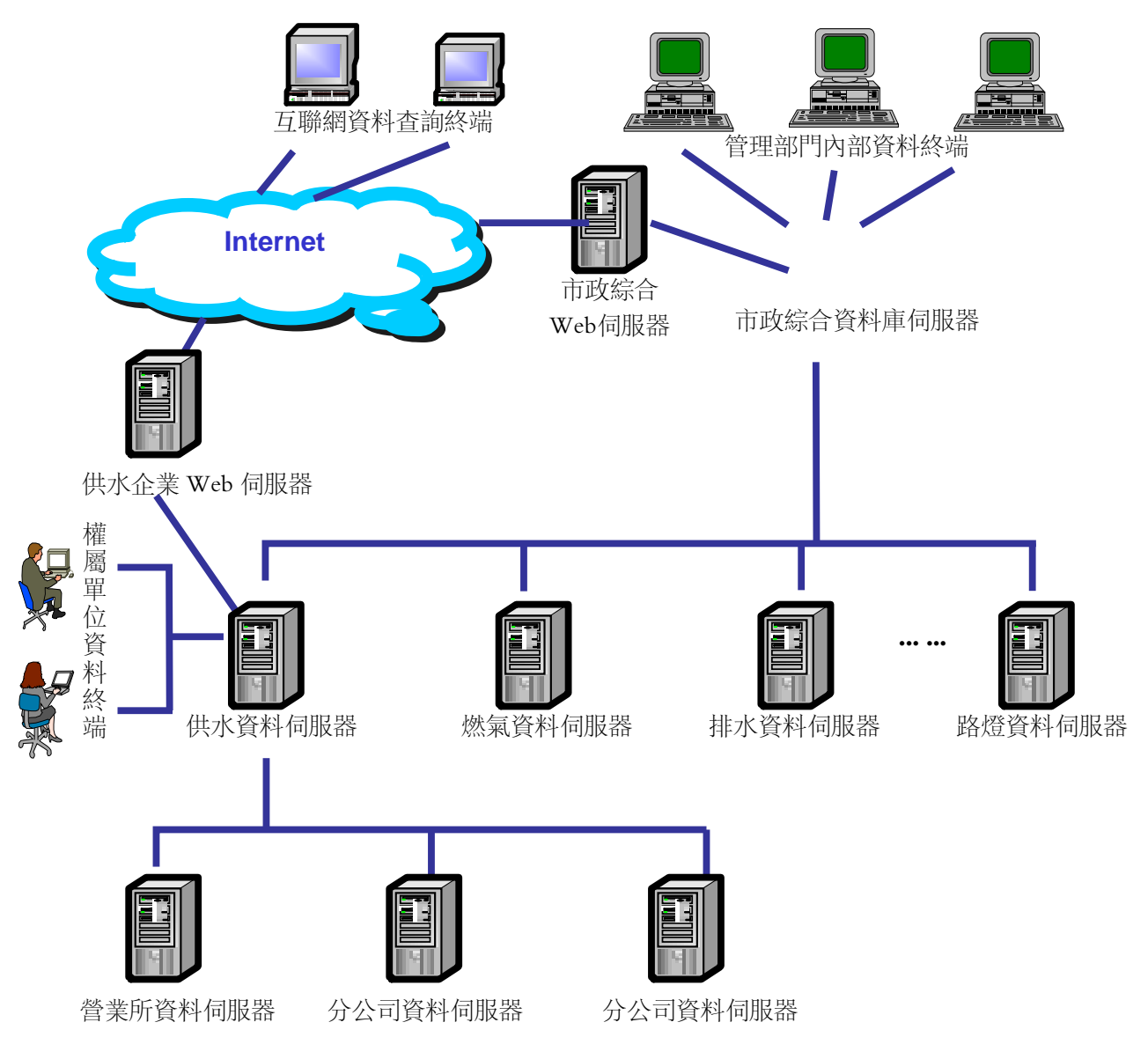

圖 1. 多級分散式資料管理體系

搭建和業務協同功能, 支援用戶對應用模型進行定 義, 並靈活配置系統。這種建設方式無需專深的開發 技巧, 系統管理者只需要掌握視覺化業務建模工具, 就可以自行對系統進行維護和完善, 得到一個持續改 進，永續運行的“活”的管理應用系統。

\section{5 系統安全}

市政設施被認為是城市運行的生命線, 市政 資訊化平臺不論從系統和資料方面都應該充分考 慮安全性, 從硬體、系統軟體、應用軟體和管理 制度等方面，實現對系統和資料的訪問控制。從 系統安全的角度, 要保證網路通暢、負荷正常、 運行穩定, 在故障出現後能迅速恢復; 從資料安 全方面看, 要維持資料的完整準確, 防止越權訪 問、䊞取或篡改。

\section{3. 平臺建設的關鍵技術}

針對上述技術指標，基礎平臺建設依賴以下關鍵
技術:

\section{1 “3S”技術}

規劃設計、設施維護、事故搶修等市政管理業務 絕大多數都和地理位置密切相關。作為空間資訊獲 取、管理和分析處理的技術, 地理資訊系統 (Geographic Information System, GIS) 、遙感 (Remote Sensing, RS) 及全球定位系統 (Global Positioning System, GPS) (即“3S”) 成為市政管理的重要基礎工 具。目前, “3S”的研究應用開始向集成化方向發展, 為市政管理資訊化提供了更為廣闊的空間。在這種應 用背景下，GPS 主要用於即時快速提供目標（市政尋 檢人員、抄表工、搶修車等)的空間位置; RS 用於即 時或准即時地提供城市環境和市政目標的語義或非語 義資訊, 發現各種變化, 及時地對 GIS 進行資料更 新; GIS 則作為基礎平臺, 對多種來源的時空資料進 行集成管理和綜合處理，並為智慧化市政資料獲取提 供地學知識[2]。 


\section{2 面向服務的架構 ( Service Oriented Archi- tecture, SOA )}

OASIS 標準組織在 SOA 參考模型中對 SOA 的定 義為: SOA 是一種軟體體系結構範型, 可以組織和 使用處於不同所有者控制下的分散式功能[3]。它描 述了一種資訊基礎設施, 使得不同的業務服務可以相 互交換資料, 參與業務流程, 通過靈活的互相協作方 式來完成具體的業務操作。這些業務服務獨立於編程 語言，獨立於實現方法，獨立於運行環境。

SOA 改變了以往以技術為中心的資訊系統建設 模式，使得資訊系統重新回歸到業務支撐的角色，為 業務、應用服務。業務人員可以像組裝硬體一樣從業 務角度即時構造應用, 從而縮小業務和技術的鴻溝。 SOA 主要通過複用性、靈活性和共用性從技術上支 援上述目標, 強調服務之間的在介面、技術和流程三 個方面的松耦合[4]。

各類市政管理資訊系統的普遍要求是：業務機 動、資源集成、構建迅捷、維護簡化、增量推進, 這 些要求恰恰是 SOA 的優勢所在。因此, 基於 SOA 框 架建立城市市政管理資訊化基礎平臺, 將使目前國內 市政管理資訊化工作突破資源割裂、建設分離、投資 重複、效率低下的瓶頸, 步入持續、快速、聚合的發 展軌道。

\section{3 標準規範體系}

市政公用事業涉及到的設施和業務資訊來源眾 多, 格式各異, 這給資訊共用帶來了不便。集成市政 管理資訊，首先必須統一市政資料分類編碼標準，形 成標準化的資料交換體系以及系統開發技術規程與系 統建設運行模式。市政資訊分類編碼和資料交換體系 是實現市政資訊有效管理、資料共用和動態更新的基 礎[5]。

為了保證標準規範體系的落實, 基礎平臺必須提 供相應的技術支援。例如, 需要建立資料編碼引擎, 批量、動態地生成和維護分類編碼。

從平臺構架實現的角度看, SOA 技術涉及眾多 標準，包括服務描述註冊標準、服務通訊標準、服務 流程標準、事務性標準等等。雖然某些廠商或聯盟提 出了一系列規範, 但權威的通行標準尚未形成。建設 市政管理資訊化基礎平臺, 需要進行慎重深入的標準 分析。

\section{4 資料交換和資料綜合技術}

資料交換包含兩個方面的含義，一是不同地理參 照體系、不同資料格式間的變換; 二是不同網路節點 間資料的分發和傳輸。市政資料的多源多尺度特性， 決定了資料交換中心是市政資料共用和應用服務的關 鍵技術支撑。

在資料交換過程中，不僅僅資料形式發生變化， 內容也有可能改變。專業權屬單位所管理的設施及業 務資料與政府綜合管理部門所管理的資料在詳盡程度 上有明顯差異，前者更詳盡，後者則是前者在城市規 劃意義上的綜合。這意味著資料的動態更新並不是簡 單的資料庫記錄複製。為了在整個城市範圍內分散存 在的、詳盡程度不一的市政資料庫之間，保持資料動 態更新和全局現勢性，市政資料綜合技術。對於空間 資料, 要擴展製圖綜合的理論和方法來處理基礎地形 和管網設施從二級專業資料到一級綜合資料之間的變 換; 對於以資料庫表形式存在的業務資料, 則需要使 用資料倉庫實施資料清洗抽取的相關技術。

\section{4. 基於 SOA 的基礎平臺總體框架}

基於 SOA 的市政資訊化基礎平臺採用層次結構 體系，主導思想是：以資料為基礎，以管理為中心， 以服務為橋樑，以業務為導向，以集成為目標。平臺 主要由軟硬體支撑層、資料層、基礎管理層、運營服 務層、應用層等 5 個部分組成，同時集成標準規範體 系和安全技術體系。各層都以其下層提供的功能或服 務為基礎。見圖 2。

以下介紹平臺中涉及的各個部分。

軟硬體支撑層是整個平臺運行的物質基礎。其中 硬體包括網路設備、伺服器、存儲備份設備等, 電腦 網路包括政府專網、公眾服務網、移動通信網、互聯 網等; 系統軟體涉及作業系統、資料庫管理系統、鏡 像及備份工具等。

資料層是系統資料存儲中心，包括市政行業專業 資料庫、市政綜合資料庫和城市基礎資料庫，在各個 資料庫中包含空間資料、業務資料、運行支撑資料、 元資料等。例如，供水行業資料庫包含管網設施、營 業收費、工程施工、即時監測、辦公案卷等方面的資 料; 城市基礎資料庫包含基礎地形、社會經濟資料等。 在各個資料庫之上，資料層提供基礎驅動工具和資料 引擎，以便對資料庫進行邏輯和語義層次上的訪問。 如前所述，在實際的市政應用中，各個資料庫是以分 散式多級方式部署的。 


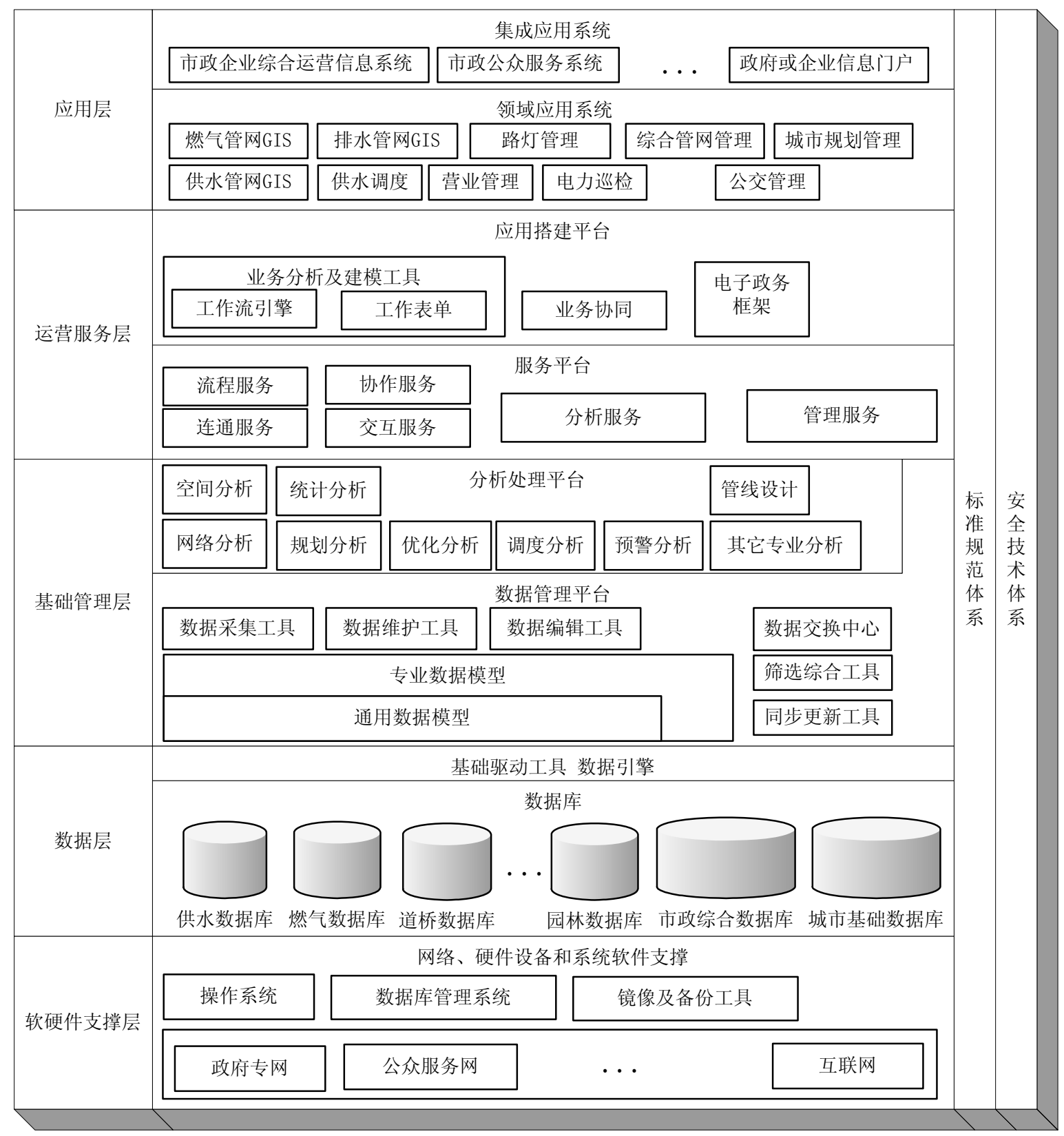

圖 2. 基於 SOA 的市政管理資訊化基礎平臺總體框架

基礎管理層包含資料管理平臺和分析處理平臺, 為各類市政應用提供基礎工具集。資料管理平臺集成 市政領域通用資料模型和專業資料模型[6],包含資料 交換中心、篩選綜合工具 ( 用於市政專業資料到城市 綜合資料之間的變換，見[1]）、同步更新工具（維持 專業資料與綜合資料的一致性）、資料獲取工具（提 供外業資料探測採集、竣工圖解析採集、GPS 資料讀 入採集、格式轉換採集等方式以及批量建庫支援）、
資料編輯工具（支援互動式和非互動式局部資料更 新）、資料維護工具（支援編碼生成維護、資料完整 性自動維護和手工檢查，保持資料關聯）等; 分析處 理平臺提供空間分析、網路分析、統計分析、規劃分 析、優化分析、調度分析、預警分析、管線設計等工 具, 還包括面向具體行業的其他專業分析, 如燃氣、 自來水管網中的爆管、漏水漏氣分析, 電網中的停電 分析、潮流分析等。 
運營服務層為市政應用系統構建提供服務封裝和 業務支援, 包括服務平臺和應用搭建平臺。服務平臺 提供管理服務、分析服務、連通服務、協作服務、流 程服務等。分析和管理服務中又可以劃分為通用服務 和專業服務，通用服務包括資料訪問查詢、元資料發 佈、投影轉換、製圖輸出、空間定位等服務，專業服 務面向各專業，提供爆管事故處理、停電分析、水費 生成等服務。應用搭建平臺包含業務分析建模工具、 業務協同工具、電子政務框架等。為了實現可配置的 協同辦公，平臺集成符合國際工作流協會 ( WFMC) 標準的工作流引擎，囊括用戶管理、業務流程的定義 和修改、路徑控制、催辦督辦等功能。

應用層包含各類市政應用系統。這些應用系統有 面向特定市政行業的專業系統 (如供排水管網地理資 訊系統、供水調度系統、營業管理系統、電力巡檢系 統、公交管理資訊系統、市政工程管理系統、城市道 橋管理系統等）；也有面向城市市政管理業務的綜合 系統 (如城市綜合管網資訊系統、城市規劃管理系統 等）; 還有面向企業或城市的應用集成系統（如供水 企業綜合運營資訊系統、城市市政公眾服務系統、資 訊門戶等）。在組合使用下層提供的服務時, 這些應 用系統具體形態是多樣的, 既可以是流覽器/伺服器 $(\mathrm{B} / \mathrm{S})$ 模式, 也可以是客戶機/伺服器 ( C/S ) 模式, 還可以是移動設備/伺服器 $(\mathrm{M} / \mathrm{S})$ 模式。

標準規範體系是系統正常運行的重要保障, 包含 兩方面的含義：資料標準化和管理標準化。資料標準 化是指標對空間資料及相關業務資料標準化體系的建 立; 管理標準化是指制定市政單位的工作規範、協作 制度、考核標準等以健全日常工作體系。

資訊安全體系充分考慮各層次的安全措施和安全 技術手段, 通過軟硬體技術和安全管理手段以保證系 統在安全穞定的環境中運行。提供鏡象備份等冗餘機 制, 保障系統健壯性, 通過機房管理、內外網隔離、 CA 認證、資料加密、許可權控制等安全機制實現合 法化訪問。以許可權控制為例, 在市政多層管理體系 下，平臺允許管理員為每個系統訪問者指定單位、部 門和職務, 控制其對每個功能和服務的訪問許可權。 考虑到市政管理的獨特性, 許可權認證還能控制對空 間區域和管理物件的訪問。例如, 各分公司全體人員 都只能修改本單位管轄的管網設施資料, 不能修改城
市其他區域管網; 自來水公司搶修班人員只能改動供 水管網閥門資料, 不能變動其他設施。通過功能表和 頁面的過濾編排機制, 擁有不同許可權的訪問者, 將 自動面對不同的操作介面。

\section{4. 總結}

市政管理資訊系統是多級分散式一體化系統, 共用與集成是市政資訊管理的必然趨勢, SOA 是解 決共用、集成和分佈的有效技術手段。基於 SOA 構 架的市政管理資訊化基礎平臺的建設，既提供專業 管理和分析功能，又提供綜合資料提取分析和規劃 設計工具; 既面向企業機構的內部提供應用集成方 案, 又面向整個城市提供分散式一體化資訊管理方 案，使城市市政管理部門及專業權屬單位之間的達 成資料共用和功能集成, 各單位可以在平臺上有針 對性地開發和應用業務系統, 充分利用機房、網路、 安全、基礎軟體等公共資訊化設施, 達到了避免重 複建設的目標。該平臺多層次、多元化的資訊服務, 為市政單位的各項業務提供了有力支撑, 是數字城 市的重要基礎設施之一。

市政資訊化基礎平臺的未來發展的重要方向之 一, 是將SOA與網格計算 (Grid Computing) 相結合, 形成以服務為導向的網格計算。網格計算是利用互聯 網技術, 把分散在不同地理位置的計算機組成一台虛 擬超級電腦, 是一個由各種計算資源組成的統一環境 [7]。計算網格提供了資源整合和共用的平臺, 服務可 以在網格中部署和調用執行, 商業邏輯和服務調用也 被當成網格程式一樣在平臺上運行, 因而十分適合作 為SOA架構的實施平臺。以服務為導向的網格計算將 提升整個市政行業資訊系統的規劃部署、運行和管理 機制。

\section{參考文獻 (References)}

[1] 曾文, 張德津. 基於 GIS 的市政管理資訊集成方案及 關鍵技術 [J]. 地球科學一一中國地質大學學報, 2006, 31(5): 688-692.

W. Zeng and D. J. Zhang. Scheme of key techniques for GIS-based integration of municipal management information [J]. Earth Science-Journal of China University of Geosciences, 2006, 31(5): 688-692. (in Chinese with English abstract).

[2] 吳信才. 地理資訊系統原理、方法及應用. 北京: 電子 工業出版社, 2002, 213-214. 
X. C. Wu . The principle, method and application for geographic information system. Beijing: Publishing House of Electronics Industry, 2002, 213-214. (in Chinese).

[3] OASIS. Reference model for service oriented architecture 1.0. OASIS 2006, Website at: http://www.oasis-open.org/ committees/tc_home.php? wg_abbrev=soa-rm.

[4] 長風開放標準平臺軟體聯盟. SOA電子政務總體技術 架構與解決方案, 2006.

C. Feng. Open standards platform software alliance. SOA Technical Framework and Resolution for E-Government, 2006.

[5] 閻正, 蔣景睲, 何建邦, 等. 城市地理資訊系統標準化
指南. 北京: 科學出版社, 1998, 20-21.

Z. Yan, J. T. Jiang, J. B. He, et al. Manual of standardization of urban geographic information systems. Beijing: Science Press, 1998, 20-21. (in Chinese).

[6] 張書亮, 等. 設備設施管理地理資訊系統. 北京: 科學 出版社, 2006, 70-97.

S. L. Zhang, et al. Introduction to AM/FM/GIS. Beijing: Science Press, 2006, 70-97. (in Chinese).

[7] I. Foster, C. Kesselman. The grid: Blueprint for a new computing infrastructure. San Francisco, CA: Morgan Kaufmann Publishers, 1999. 
